\title{
Seleção e uso de recursos instrucionais aptos ao estabelecimento de distância transacional adequada em cursos a distância.
}

\author{
Luís Alberto Guadagnin*, \\ Renato Luis De Souza Dutra**, \\ Liane M. R. Tarouco ${ }^{* * *}$
}

Resumo. O artigo se propõe a contribuir para o processo de seleção e utilização de recursos tecnológicos, em cada curso a distância, aptos ao estabelecimento da distância transacional apropriada. A otimização dos resultados a serem alcançados pela EAD demanda a configuração de recursos e estratégias mais adequada para cada curso, consideradas as especificidades do público-alvo, do tema e do estágio atual de desenvolvimento tecnológico das ferramentas de EAD e dos recursos instrucionais multimídia.

Palavras-chave: educação à distância, recursos tecnológicos, distância transacional.

\footnotetext{
Doutorando no PGIE/UFRGS, Mestre em Administração, Professor do NAVI/EA/UFRGS e da FACE/PUCRS, Fiscal de Tributos Estaduais da Secretaria da Fazenda do RS (luisguadagnin@via-rs.net).

" Doutorando no PGIE/UFRGS, Mestre em Ciência da Computação

*** Doutora .....

V.1 No 2, Setembro, 2003
} 


\section{INTRODUÇÃO}

Organizar, implementar e administrar processos de aprendizagem a distância implica na avaliação prévia das alternativas de estratégias a adotar. Na educação desenvolvida por meio de cursos presenciais aloca-se um espaço físico para funcionar como sala de aula, estipulam-se horários fixos para as atividades de ensino; definem-se datas para início e término do curso; há a proximidade física professor-alunos. Diferentemente, na Educação a Distância mediada por computador não se fazem presentes tais características. Ao invés disso, há necessidade de: adequada preparação de recursos instrucionais multimídia, construção de ambiente virtual, seleção de recursos de interatividade, prospecção remota do perfil e das expectativas dos alunos, definição dos papéis a serem exercidos por professores e tutores; elaboração de plano delineando a interação e os desafios a serem propostos. O dinamismo da evolução tecnológica propicia, em ciclos sempre menores, inovações que ampliam e qualificam as ferramentas utilizadas como suporte para a EAD. A disseminação do acesso à Internet permite superar barreiras geográficas e sociais. A aceleração da obsolescência dos saberes amplia a demanda por atualização profissional continuada, insuficiente ou inadequadamente atendida pelos cursos presenciais de escolas e universidades. Neste contexto, a otimização dos resultados a serem alcançados pela EAD demanda o planejamento estratégico da configuração mais adequada para cada curso. O presente artigo se propõe a contribuir no processo de seleção e uso dos recursos tecnológicos apropriados para o estabelecimento de distância transacional que propicie a melhor dosagem de diálogo, estrutura e autonomia, em cada curso.

\section{DISTÂNCIA TRANSACIONAL.}

Desde a Grécia antiga educação envolve proximidade física de docentes e discentes. A tendência para estabelecer dicotomias, reforçada pela hegemonia do modelo cartesiano-mecanicista que imperou do século XVIII a meados do século XX, quando ocorreu a universalização do acesso à escola, consagrou a proximidade física como requisito para a aprendizagem e, por outro lado, a distância como um déficit a ser superado. As primeiras tentativas para estabelecer princípios didáticos específicos para a educação a distância, mesmo nos modelos baseados no ensino por correspondência, privilegiaram a busca de meios e caminhos para "superar, reduzir, amenizar ou até mesmo anular a distância física" (Peters, 2001, 47). Diferenciando distância física de distância comunicativa ou psíquica, Michael Moore (1993, 22) introduz o construto teórico de distância transacional. O construto é uma construção lógica de um conjunto de propriedades aplicáveis a elementos reais. Possui um significado construído intencionalmente a partir de um marco teórico, devendo ser definido de tal forma que permita ser delimitado, traduzido em proposições particulares observáveis e mensuráveis. A elaboração do construto consiste em (Quivy \& Campenhoudt, 1998, p. 123): a) "determinar as dimensões que o constituem, através das quais dá conta do real"; b) precisar os indicadores, que são "manifestações objetivamente observáveis e mensuráveis das dimensões do conceito". Elabora-se, no quadro que segue, o construto teórico de distância transacional. 


\begin{tabular}{|c|c|c|}
\hline \multicolumn{3}{|c|}{ Construto teórico: } \\
\hline Dimensões & \multicolumn{2}{|c|}{ Atributos extremos } \\
\hline Diálogo & $\begin{array}{l}\text { Docentes e discentes } \\
\text { não mantém qualquer } \\
\text { intercomunicação. }\end{array}$ & $\begin{array}{l}\text { Diálogos freqüentes, podendo } \\
\text { expressar-se os pré-conhecimentos, } \\
\text { interesses e desejos de cada estudante, } \\
\text { influenciando no ritmo e no rumo do } \\
\text { curso. }\end{array}$ \\
\hline Estrutura & $\begin{array}{l}\text { Ensino pré-programado } \\
\text { em todos os detalhes e } \\
\text { prescrito } \\
\text { compulsoriamente. }\end{array}$ & $\begin{array}{l}\text { Ensino customizado, valorizando a } \\
\text { experiência e a expectativa de cada } \\
\text { estudante e atendendo sua necessidade } \\
\text { específica. }\end{array}$ \\
\hline Autonomia & $\begin{array}{l}\text { Etapas e atividades do } \\
\text { ensino determinados por } \\
\text { estruturação e diálogo; } \\
\text { controle da } \\
\text { aprendizagem a cargo } \\
\text { de terceiros. }\end{array}$ & $\begin{array}{l}\text { Os próprios estudantes reconhecem } \\
\text { suas necessidades de estudo, formulam } \\
\text { objetivos, selecionam conteúdos, } \\
\text { projetam estratégias de estudo, } \\
\text { arranjam materiais e meios didáticos, } \\
\text { identificam fontes humanas e materiais } \\
\text { adicionais e fazem uso delas; eles } \\
\text { próprios organizam, dirigem, controlam } \\
\text { e avaliam o processo da aprendizagem, } \\
\text { não sendo limitados nem por diálogos e } \\
\text { nem por estruturas preestabelecidas. }\end{array}$ \\
\hline
\end{tabular}

a. Figura 1: Construto teórico da distância transacional.

Moore destaca que o desafio não consiste em suprimir a distância transacional, mas em implementá-la na dosagem adequada, em razão das características pessoais dos participantes, dos temas e objetivos propostos, e dos meios disponíveis. Cada curso requer a implementação de distância transacional específica, a ser obtida pela seleção de técnicas e estratégias que propiciem a combinação adequada das três dimensões que a definem: estrutura, diálogo e autonomia. Peters $(2001,71)$ realça a importância que o conjunto diálogo, estrutura e autonomia tem para a EAD e afirma que o diálogo didático, o estudo tecnológico pedagogicamente estruturado e o estudo autônomo não preponderam na prática do ensino superior.

\subsection{Diálogo}

Moore $(1993,24)$ confere primazia ao diálogo na estruturação do conceito de distância transacional. A aprendizagem dialogal tem papel central na pedagogia humanista, que o preconiza sem estruturas e sem fim predeterminado, exigindo parceria, respeito, calor humano, consideração, compreensão empática, sinceridade $e$ autenticidade:

Um diálogo é direcionado, construtivo e é apreciado pelos participantes. Cada uma das partes presta respeitosa e interessada atenção ao que o outro tem a dizer. Cada uma das partes contribui com algo para seu desenvolvimento e se refere às contribuições do 
outro partido. Podem ocorrer interações negativas e neutras. $O$ termo diálogo, no entanto, sempre se reporta a interações positivas. Dá-se importância a uma solução conjunta do problema discutido, desejando chegar a uma compreensão mais profunda dos estudantes.

O diálogo ativa e aprofunda a reflexão sobre os temas em estudo. Ao confrontar opiniões divergentes, assumir posicionamentos, externar dúvidas, questionar e criticar, o estudante envolve-se com o conteúdo. Diversamente, o método expositivoentregador (Dolch, 1952, apud Petters, 2001, p. 79) propicia, no máximo uma aprendizagem no sentido de apropriar-se, de guardar na memória e de reproduzir o saber quando desafiado, não contribuindo para desenvolver a capacidade de um pensar crítico autônomo, a capacidade de aplicar esse pensamento crítico, de experimentar a autonomia racional daí decorrente e de afirmar-se nisso. "É necessário que toda percepção seja uma tradução reconstrutora realizada pelo cérebro, a partir de terminais sensoriais, e que nenhum conhecimento possa dispensar interpretação" (Morin, 2002, 52). "Não tem sentido o mero repasse copiado", sustenta Demo (2001, 130). "Contato pedagógico próprio da universidade é aquele mediado pela produção/reconstrução de conhecimento". A utilização de modernas mídias para a mera exposição dos conteúdos, não ameniza e, ao contrário, pode agravar as conseqüências deletérias da ausência de produção científica própria, da falta de ênfase no aprender a aprender e da inexistência ou insuficiência do diálogo.

\section{$2.2 \quad$ Estrutura}

A estruturação pormenorizada do processo de ensino-aprendizagem é designada por Moore $(1993,26)$ como estrutura, exemplificando-a, no limite, com um filme didático pela televisão, no qual cada termo, cada movimento do docente, cada momento e cada atividade estão predeterminados. Escasso é o espaço que resta ao estudante para trilhar rumo didático diverso, adequá-lo às suas necessidades ou seguir inspirações espontâneas (Peters, 2001, 87). Adota-se o modelo behaviorista, baseado em premissas positivistas teórico-científicas e no emprego de procedimentos empíricos. A tecnologia do ensino respalda a fixação dos objetivos de ensino e aprendizagem, a escolha dos conteúdos e das estratégias, a construção de testes e o controle do sucesso objetivado.

Dentre as desvantagens dos cursos a distância excessivamente estruturados, Peters (2001, 89-92) destaca: ênfase no ensino em detrimento da participação dos estudantes, "escolarizando" de forma tendenciosa a aprendizagem; exclusão de objetivos de aprendizagem que não possam ser objeto de avaliação padronizada; escolha do caminho mais curto em direção ao alvo, inibindo a análise dos fenômenos estudados a partir de diferentes visões auto-escolhidas; proteção artificial contra as experiências do bloqueio e do fracasso; redução do complexo processo de ensino e aprendizagem a um conjunto unidimensional e linear de funções; dificulta a aprendizagem por meio de participação, reflexão e metacognição; são expressamente centrados no professor. A difusão de cursos estruturados assentou-se nas seguintes razões: 
a)

crença firmada nos anos 70 e 80 de que os procedimentos das ciências naturais e da área tecnológica poderiam ser replicados com igual êxito nas tarefas pedagógicas e didáticas: o ensino deveria ser planejado racionalmente, desenvolvido sistemicamente, melhorado com base em experiências, controlado para coibir lacunas e mensurado como algo produzido industrialmente;

b) intenção de promover oferta de ensino de qualidade elevada, pela alocação de especialistas renomados na elaboração do material didático;

c) possibilidade de oferecer mais formação para mais pessoas.

Subsidiando a tomada de decisão entre privilegiar o diálogo em detrimento da estrutura, ou a estruturação em prejuízo do diálogo, Peters $(2001,92)$ destaca que didaticamente é mais desejável a concepção do diálogo. Entretanto, apesar da coisificação do ensino na forma de sistemas de ensino minuciosamente planejados, construídos, experimentados e avaliados, a estruturação propicia a disseminação em massa e apresenta longa aprovação prática em grandes universidades a distância ou open universities.

\subsection{Autonomia}

Conforme Peters (2001, 93-104), Moore delimita autonomia à autodeterminação dos estudantes, destacando que consistiria em um comportamento natural para adultos. Peters, amplia a abrangência do conceito de autonomia, destacando as dimensões a seguir sintetizadas.

\begin{tabular}{|l|l|}
\hline \multicolumn{1}{|c|}{ Construto teórico: $\quad$ Autonomia } \\
\hline Dimensões & \multicolumn{1}{c|}{ Atributos } \\
\hline Filosófica & $\begin{array}{l}\text { Immanuel Kant queria libertar o ser humano de sua menoridade por culpa } \\
\text { própria, levando-o a fazer uso de sua razão sem ajuda alheia. Para ele, a } \\
\text { moralização tinha o primado na educação. Essa, porém, se quiser ativar a } \\
\text { liberdade moral do educando autônomo, não pode ser prescrevedora e } \\
\text { determinadora de fora, mas, sim, somente despertadora e doadora (Böhm, } \\
\text { 1994, 365). Uma de suas sentenças que, quanto ao sentido, pode ser aplicada } \\
\text { diretamente ao estudo autônomo é a seguinte: Quem educa pratica açôes, } \\
\text { cujo alvo é tornar-se supérfluo. Quem está sendo educado tem que aprender } \\
\text { a fazer ele mesmo o que até então outros fizeram por ele. }\end{array}$ \\
\hline Pedagógica & $\begin{array}{l}\text { Os seres humanos não são mais objetos da condução, influxo, ascendência e } \\
\text { coerção educacionais, mas, sim, sujeitos de sua própria educação. O ser } \\
\text { humano é obra dele mesmo. }\end{array}$ \\
\hline
\end{tabular}


Estudantes são autônomos quando assumem e executam as funções dos docentes: eles mesmos reconhecem suas necessidades de estudo, formulam objetivos para o estudo, selecionam conteúdos, projetam Didática estratégias de estudo, arranjam materiais e meios didáticos, identificam fontes humanas e materiais adicionais e fazem uso delas, bem como organizam, dirigem, controlam e avaliam o processo da aprendizagem.

Pode-se considerar estudantes como autônomos somente quando são participantes metacognitiva, motivacional e comportamentalmente ativos de

Psicológica seus próprios processos de aprendizagem; o estudo autônomo é componente de uma qualidade tipicamente humana: a ânsia de entender e regular a si mesmo.

\section{b. Figura 2: Construto teórico de autonomia}

Peters $(2001,97)$ realça: a proposta do estudo autônomo é conhecida há muito na teoria e na prática, está teoricamente elaborada e é praticada; em contraposição, os tradicionais procedimentos didáticos expositivos referem-se a um estágio passado da sociedade e são grosseiramente inadequados:

Em relação às universidades com presença isso vale especialmente para as preleções, em universidades a distância em relação aos cursos de ensino a distância preparados em detalhes. $O$ estudo autônomo, ao contrário, parece corresponder às tendências do tempo e estar aberto para o futuro.

Os estudantes que buscam cursos a distância para atualizar, qualificar e/ou complementar sua formação podem apresentar certas especificidades: maior experiência de vida e profissional; estudo em tempo parcial, paralelo a atividades laborais, sociais e familiares; busca de ascensão social; qualificação e idade média superior a dos estudantes de cursos regulares presenciais (Peters, 2001, 37-38).

\section{A DISTÂNCIA TRANSACIONAL APOIDA NA TECNOLOGIA}

A Distância Transacional é um conceito importante na EAD e para que se possa oferecer cursos à distância com qualidade é necessário buscar o nível ideal desta distância, oferecendo cursos de qualidade, estruturados que privilegiem o diálogo e autonomia. Esta visão deve ser levada em consideração no planejamento e desenvolmimentdo de cursos à distância, levando-se em consideração tanto o conteúdo a ser desenvolvido como os aspectos tecnológicos necessários para que se possa atingir um bom nível de distância transacional

O diálogo, durante o Curso, pode ser viabilizado através do contato direto e apresentação recíproca nas aulas presenciais e através da colocação dos endereços eletrônicos dos professores e dos alunos além de nomes, horários, formas e números 
para contato com o pessoal de apoio. As ferramentas de conversação síncrona (chat) poderm ser utilizadas para a realização de debates e esclarecimentos em rede, com a mediação dos professores, em datas e horários previamente definidos. As ferramentas de fórum são indicadas para discussões com mais profundidade e sua disponibilização em em tempo integral, como Fórum Permanente, propicia a cooperação e a discussão dos temas entre os participantes. Ferramentas como diários de bordo podem ser utilizados para que os alunos registrem sua evolução e dificuldades, além de fornecer um canal para a monitoração e o suporte por parte do professor e demais colegas, bem como incentivos e orientação quanto ao progresso nos estudos. Outro item importante é a utilização de ferramentas para a proposição de atividades individuais ou em grupo para propor por exemplo a resolução de casos reais com apresentação dos resultados aos participantes, via web.

A importância do diálogo não obscurece a importância da estrutura nos cursos EAD. Como dito anteriormente, cursos excessivamente estruturados não privilegiam a interação com os alunos. Por outro lado, atividades de dialogo síncrono como chats, precisam estar previamente agendadas, terem um objetivo definido e uma mediação competente, para que esta consiga seus objetivos educacionais.

Outro fator a ser considerado é que devido a cultura educacional em nossas instituições e a legislação, os cursos EAD precisam ter requisitos mínimos como freqüência mínima, avaliações e período de realização pré-determinado. Os próprios documentos elaborados para fins de aprovação de cursos de graduação e pós-graduação contém informações como estrutura do curso, objetivos, ementas, modelo de avaliação, bibliografia etc. Cursos como a Especialização em Informática na Educação (PGIE) e o Mestrado em Educação a Distância (PPGEDU), possuem uma estrutura bem definida de disciplinas, diálogos síncronos, avaliações e aulas presenciais. Isto indica que mesmo o diálogo sendo um fator importante os cursos EAD precisam ter um estrutura.

Para que esta estrutura seja implementada de forma qualitativa o primeiro passo e apresentar esta esta estrutura, por mínima que seja, no inicio do curso, ou seja na introdução, visto que segundo Peters. São necessárias também ferramentas para o agendamento de atividades, nas quais o professor pode agendar diálogos síncronos, entrega de trabalhos e estudos individuais. Os testes on-line são outro importante recurso para fixar e estimular a aprendizagem. Indicações de materiais de apoio e possibilidade de criar discussões (fóruns) temáticas, são características necessárias para se direcionar as discussões. Os sistemas de gerenciamento de aprendizagem profissionais e acadêmco, tais Aulanet, Teleduc, eProinfo, LearningSpaece normalmente implementam estes recursos.

Junto ao dialogo e a estrutura, a autonomia é o terceiro componente a ser apoiado na EAD visando diminuir a distância transacional. Apesar da autonomia ser historicamente ligada ao estudo individual, eles não são sinonimos. A autonomia está mais ligada a liberdade e auto regulação e estas características não são exclusivas do individuo e podem também ser exercidas em grupos, que podem surgir por indicação do professor ou também por iniciativa dos próprios participantees. Esta consideração é importante visto que Para se apoiar a autonomia deve-se disponibilizar ferramentas que apóiem os alunos no processo de auto-estudo e auto-organização, visto que justamente por sua autonomia necessitam ter uma maior disciplina e controle de suas atividades. Entre estas ferramentas podemos citar as agendas pessoais e o diário de bordo, complementando a agenda de atividades do curso. As discussões assíncronas são recursos importantes, pois além de potencializar o diálogo oferecem a flexibilidade necessária a autonomia. No auto-estudo a metacognição é um aspecto importante visto que através dela o aluno vizualiza seu proceso cognitivo e determine suas ferramentas mais úteis e seu ritmo de aprendizado. $\mathrm{O}$ aluno deve, então ser 
estimulado neste processo através e os cursos devem disponibilizar ferramentas que auxiliem neste processo, tais como diário de bordo e auto avaliação.

\begin{tabular}{|l|l|}
\hline & Ferramentas e Recursos Tecnológicos \\
\hline Diálogo & $\begin{array}{l}\text { Chats, Fóruns, Diário de Bordo, Gerenciador de Atividades, Resolução de } \\
\text { Problemas }\end{array}$ \\
\hline Estrutura & $\begin{array}{l}\text { Gerenciador de Atividades, Agenda do curso, Descrição on line do Curso, } \\
\text { Testes on-line, Fórum flexível }\end{array}$ \\
\hline Autonomia & $\begin{array}{l}\text { Fórum, Agenda Pessoal dos alunos, Diário de Bordo, Ferramentas } \\
\text { Cognitivas (diagramas e mapas) }\end{array}$ \\
\hline
\end{tabular}

\section{c. Quadro 1 - Resumo de recursos disponíveis para a Distância Transacional}

A interface também das ferramentas também deve ser levada em consideração quando se fala em autonomia, visto que eelapode ser um dos sesinteragir com, com o professor e seus colegas de cruso. $\mathrm{P}$ e

\section{CONCLUSÃO.}

Nos cursos à distância, o ideal é que a metodologia a ser adotada deva agilizar o processo de criação, transmissão, atualização e disseminação do conhecimento, com menor custo, garantindo a melhoria contínua na criação, aperfeiçoamento e divulgação de conhecimentos. Busca-se, com a EAD, propiciar acesso ao conhecimento e o desenvolvimento de hábitos, habilidades e atitudes relativos ao estudo, à profissão e à própria vida dos participantes, através de cursos bem estruturados, que possam ser freqëntados no tempo e local que lhe sejam mais adequados, com a mediação de professores (orientadores/tutores), atuando ora a distância, ora em presença, e com o apoio de materiais didáticos sistematicamente organizados, apresentados em diferentes suportes de informação, utilizados isoladamente ou combinados, e veiculados nos diversos meios de comunicação e interação disponíveis.

Este equilibrio entre diálogo, estrutura e autonomia é o objetivo maior buscado no planejamento de desenvolvimento de cursos à distâncial. Atualmente existem diversos recursos e ferramentas que suprem de diversas maneiras estes três componentes. A cada dia mais sistemas de gerenciamento de aprendizagem, incorporam estes recursos e ferramentas, oferecendo a flexibilidade para que cada professor configure o exato nível de Distância Transacional desejado. O grande desafio é como melhor utilizar estes recursos, qual o nível ideal para cada curso e quais as abordagens e metologias a serem empregadas.

\section{Referências Bibliográficas:}

BELLONI, Maria Luiza. Educação a distância. Campinas, SP : Ed. Autores Associados, 2001. 2 ed.

CASTELLS, Manuel. A sociedade em rede a era da informação: economia, sociedade e cultura. São Paulo : Paz e Terra, 1999. 
DEMO, Pedro. Educação e conhecimento: relação necessária, insuficiente e controversa. Petrópolis : Vozes, 2000.

Desafios modernos da educação. $11^{\text {a }}$ ed. Petrópolis : Vozes, 2001.

GUADAGNIN, Luís Alberto. Avaliação do Impacto da Aprendizagem Organizacional de Duplo Circuito na Concepção de um Sistema de Informação. Porto Alegre : 2000. Dissertação (Mestrado em Administração) - PPGA/UFRGS. Orientadores: Prof. Dr. Norberto Hoppen e Prof. Dr. Eugenio Lagemann.

A concepção acadêmica de um sistema de informação e sua implantação em 497 municípios. Porto Alegre : 2002. Artigo publicado e apresentado no XXXVII Congresso Latino-americano de Escolas de Administração.

GUADAGNIN, Luís Alberto; KLERING, Luis Roque; BIANCAMANO, Mary; KIHS, Marco Aurélio; e PILLA, Bianca Smith. Educação a distância para gestores locais: potencialidades e desafios. Porto Alegre : 2002. Artigo publicado e apresentado no XXXVII Congresso Latino-americano de Escolas de Administração.

MARSHALL, Stephanie Pace. Criando comunidades vigorosas centradas no aprendizado para o século XXI. In HESSELBEIN, Frances et al. A Organização do Futuro: como preparar hoje as empresas de amanhã. São Paulo : Futura, 1997.

MEISTER, Jeanne C. Educação corporativa: a gestão do capital intelectual através das universidades corporativas. São Paulo : Makron Books, 1999.

MORIN, Edgar. A cabeça bem-feita: repensar a reforma - reformar o pensamento. $7^{\text {a }}$ ed. Rio de Janeiro : Bertrand Brasil, 2002.

PALLOFF, Rena M. e PRATT, Keith. Construindo comunidades de aprendizagem no ciberespaço. Porto Alegre : Artmed, 2002.

PETERS, Otto. Didática do ensino a distância. São Leopoldo : UNISINOS, 2001.

PIAGET, Jean. A epistemologia genética / Sabedoria e ilusões da filosofia / Problemas de Psicologia genética. São Paulo : Abril Cultural, 1983. Coleção "Os Pensadores".

QUIVY, Raymond e CAMPENHOUDT, Luc Van. Manual de investigação em Ciências Sociais. 2 ed. Lisboa : Gradiva, 1998.

TAPSCOTT, D. e CASTON, A..Mudança de paradigma: a nova promessa da Tecnologia da Informação. São Paulo : Makron Books, 1995.

TAPSCOTT, Don. Economia Digital: promessa e perigo na era da inteligência em rede. São Paulo : Makron Books, 1997. 